\title{
Obesity and related risk factors in gastric cardia adenocarcinoma
}

\author{
Sidney Olefson $\cdot$ Steven F. Moss
}

Received: 29 May 2014/Accepted: 23 August 2014/Published online: 11 September 2014

(C) The International Gastric Cancer Association and The Japanese Gastric Cancer Association 2014

\begin{abstract}
Over recent decades, the incidence of cancers of the gastroesophageal junction, including gastric cardia tumors, has increased markedly. This is a trend that has been well documented, especially in studies from the USA and northern Europe that have also demonstrated a concomitant rise in the ratio of cardia to distal gastric cancers. The rise in the prevalence of gastric cardia adenocarcinoma has been paralleled by the worldwide obesity epidemic, with almost all epidemiological studies reporting increased body mass index and obesity increase the risk of cardia cancer development. However, the strength of this association is less marked than the link between obesity and esophageal adenocarcinoma, and the mechanisms remain poorly understood. Other possible confounders of the relationship between obesity and cardia cancer include the decline in Helicobacter pylori infection and the widespread use of proton pump inhibitors, although these have rarely been controlled for in case-control and cohort studies investigating associations between obesity and cardia cancer. We review these epidemiological trends and discuss proposed mechanisms for the association, drawing attention to controversies over the difficulty of defining cardia cancer. The relative paucity of high-quality epidemiological studies from other regions of the world should prompt further investigation of this issue, especially in populations undergoing rapid socioeconomic change.
\end{abstract}

S. Olefson · S. F. Moss $(\square)$

Department of Medicine, Rhode Island Hospital, Warren Alpert Medical School of Brown University, Providence, RI 02903, USA

e-mail: steven_moss@brown.edu
Keywords Gastric cardia cancer - Epidemiology · Obesity $\cdot$ Body mass index $\cdot$ Helicobacter pylori

\section{Introduction}

The incidence of cancers of the gastroesophageal junction, including gastric cardia adenocarcinoma (GCA), has increased markedly over the past 50 years [1]. This rise was first emphasized in the USA and northern Europe, where a concomitant rise in the ratio of GCA to distal (noncardia) gastric cancers has also been evident [1-3], but it has also more recently been reported in many other regions of the world [4]. The increased prevalence of GCA has accompanied the global obesity epidemic, with almost all epidemiological studies reporting an association between increased body mass index (BMI) and/or obesity and the risk of GCA development.

Explaining this disturbing rise in GCA prevalence and the parallel rise in BMI and/or obesity has been a challenging and active area of research. It involves teasing out demographic and behavioral patterns that have occurred over the same timeframe, together with elucidating and testing proposed pathogenic mechanisms. In this review, we will discuss some of the most recent research on epidemiological trends and tested/proposed mechanisms for the rise in GCA prevalence. We focus here on BMI, for which there is the most evidence, but also consider other interrelated variables that may have confounded this relationship. These include an increasing prevalence of gastroesophageal reflux disease (GERD) and diabetes mellitus (DM), the decline in Helicobacter pylori infection in the Western world, and the widespread use of acid inhibitory medications, especially the proton pump inhibitors. But first, what is known of the descriptive epidemiology of gastric cancers? 


\section{Gastric cardia cancer: descriptive epidemiology}

Epidemiological studies of cancer over the past few decades have revealed significant declines in death from many solid tumors in the USA, including cancers of the lung, prostate, colon, and breast. One of the most striking decreases has been for gastric cancer-from 36 and 42 deaths per 100,000 population per year in 1930 (male and female, respectively) to an estimated five and two deaths per 100,000 population per year in 2010 [4]. Among distal gastric cancers, which are the most prevalent type of gastric neoplasm, the decline was about $2.0 \%$ per year between 1977 and 2006 [2], showing an approximately equal rate of change among whites (from 5.9 to 4.0 deaths per 100,000 population) and blacks (from 13.7 to 9.5 deaths per 100,000 population). However, for GCA, the trend is quite different-instead, there has been an increase in annual incidence, from ten cases per million population in 1973 to over 20 cases per million population in 2010 [3], including an annual increase of $5.2 \%$ between 1973 and 1985. The rise in the annual incidence of GCA in the USA has coincided with an epidemic of esophageal adenocarcinoma (EAC), soaring from 2.5 cases per million population to nearly 30 cases per million population over the same time [3].

Similar changes have been observed in many other fully industrialized Western countries. The proportion of GCA among overall gastric cancers is currently highest in the UK (54.2\% of cases for males) and in Australia and New Zealand combined (46.4\% among males), compared with Japan and southern Europe, where GCAs comprise only 14.9 and $18.8 \%$, respectively, of the gastric cancer burden [3].

Gastric cancer is particularly prevalent in Southeast Asia, where China, Japan, and Korea account for $60 \%$ of cases [5]. In Asia, gastric cancer has not shown such a marked decline as noted in Western countries [5, 6], yet, similarly to the West, the incidence of GCA has risen. One registry in Singapore reported that the gastric cardia cancer rate increased from $6.3 \%$ of all gastric cancers in the 1968-1982 period to $20.1 \%$ in the $2000-2005$ period [7].

\section{The gastric cardia and GCA: anatomy and definitional issues}

The gastric cardia is an anatomically small $(1-2 \mathrm{~cm}$ or smaller) region just distal to the gastroesophageal junction that is defined by branched, tubular mucous-secreting gastric glands lacking the specialized acid-secreting parietal cells and pepsinogen-secreting chief cells that characterize the oxyntic mucosa of the gastric fundus and body [8]. Because the incidence and extent of the cardiac glands

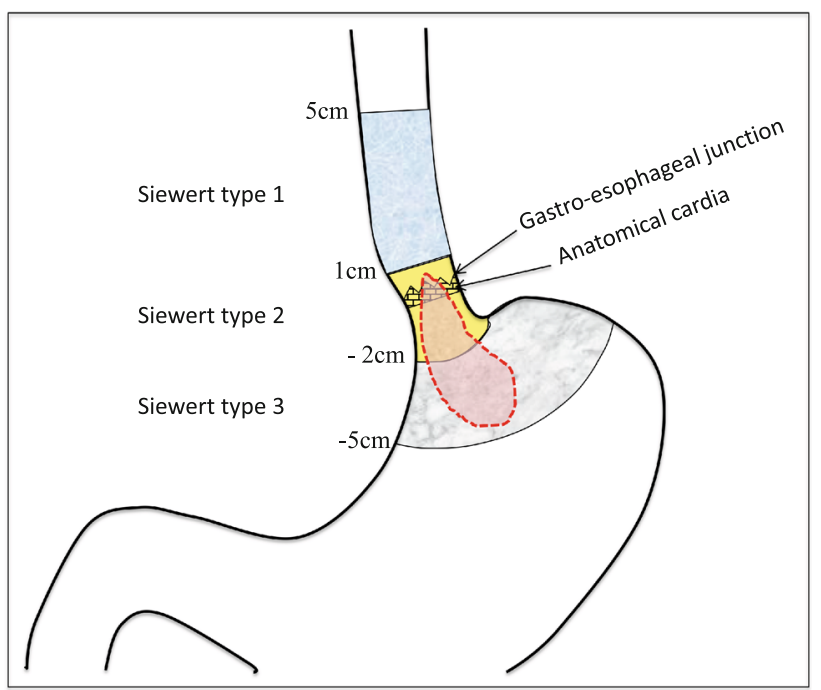

Fig. 1 Anatomy of the gastroesophageal junction for tumor staging. Shown on the left is the modified Siewert classification of tumors of the gastroesophageal junction in which the tumor type is determined by the tumor epicenter. Tumors of type 2 and 3 extending across the gastroesophageal junction were defined as gastric cardia tumors in the sixth edition of the American Joint Commission of Cancer (AJCC) staging system (2002), whereas in the current, seventh, edition (2010), a cardia cancer is defined by (1) the midpoint of the tumor lying more than $5 \mathrm{~cm}$ from the gastroesophageal junction and extending across it, or (2) a tumor arising within $5 \mathrm{~cm}$ of but not extending into the gastroesophageal junction. As an example, the tumor shown here (broken red lines) would be classified as gastric cardia according to sixth edition of the AJCC staging system but as an esophageal lesion according to the seventh edition of the AJCC staging system

were linked to excessive gastroesophageal reflux, this led Chandrosoma et al. [9] to speculate that cardiac glands may be an acquired change from esophageal squamous mucosa. However, cardiac glands were subsequently identified in most children, the newborn, and even in fetuses [10-12], suggesting that they are present from early in life, representing a functionally distinct, albeit small, anatomical region of the normal stomach.

Nevertheless, as pointed out by McColl [13], the definition of the normal cardia remains problematic. This is especially so for endoscopic biopsies, because true cardiac glands may be indistinguishable histologically from gastric metaplasia in the lower esophagus secondary to GERD, or from oxyntic mucosal glands that have undergone atrophic change (with loss of oxyntic and chief cells) due to chronic $H$. pylori infection. The site of the biopsy should help distinguish among these possibilities, but in the presence of a hiatal hernia, Barrett's esophagus, and a retching patient the endoscopist may not be certain which of these regions were actually sampled.

Definitional issues regarding the normal cardia, not surprisingly, translate into controversy over the definition and origins of gastric GCA (Fig. 1). Since the 1990s the 
Siewert classification system for gastroesophageal junction tumors has been in common use by surgeons and pathologists throughout the world [14]. In this schema, type 1 tumors are those that have their epicenter in the lower esophagus, type 2 tumors arise from an area $1 \mathrm{~cm}$ proximal to $2 \mathrm{~cm}$ distal to the gastroesophageal junction, and type 3 tumors originate $2-5 \mathrm{~cm}$ distally. Type 1 tumors have been generally managed like EAC, with type 3 tumors treated as for distal gastric cancer, whereas the management and staging of the type 2 tumors has been controversial. The definition of GCA according to the sixth edition of American Joint Commission of Cancer (AJCC) staging system (2002) corresponds to Siewert types 2 and 3 and to the International Classification of Diseases for Oncology (ICD-O) code C16.0. This has generally been that used in clinicopathology studies and, as will be discussed later, has been the default definition for GCA used in most of the epidemiological literature.

However, in the seventh edition of the AJCC cancer staging manual published in 2010 [15], gastroesophageal junction tumors were redefined significantly. In this new classification, gastroesophageal junction tumors that cross the gastroesophageal junction and that have a midpoint within the upper stomach up to $5 \mathrm{~cm}$ from the gastroesophageal junction (previously classified as Siewert types 2 and 3) are now considered to be esophageal cancers. According to the seventh edition of the AJCC staging system, a GCA is a tumor that either arises from a distance of at least $5 \mathrm{~cm}$ from the gastroesophageal junction at its midpoint or lies within $5 \mathrm{~cm}$ of the gastroesophageal junction but does not cross it. As might be expected, this change in classification has been somewhat controversial, and the southward (distal) migration of GCAs inherent in this redefinition has probably changed views on the pathogenesis. It is not clear exactly what led to the change in classification, although it was probably related to the realization that, in the USA, gastroesophageal junction cancers share many features with EAC, including an association with obesity and reflux disease, the presence of a normal distal gastric mucosa (without H. pylori gastritis), and similarities in their molecular genetics and prognostic staging [16-18].

It is also debatable whether this redefinition is appropriate for the GCAs occurring in Chinese patients, where reflux disease is usually absent and $H$. pylori gastritis is highly prevalent [19]. To add to the controversy about cancers arising from the lower esophagus and upper stomach, McColl and Going [20] have even proposed that the terms "gastroesophageal junction" and "cardia" should be discarded for tumors. In their view, if the lesion has an intestinal morphology (most of such tumors found at the gastroesophageal junction), it should be classified as either esophageal or gastric, depending on the absence of $H$. pylori and the presence of reflux (for an esophageal tumor), with the reverse being true for gastric tumors. This debate regarding the origins and definitions of tumors of the gastroesophageal junction is not merely academic, since the definitional problems outlined above continue to plague epidemiological and other studies that address the causes and associated factors for these tumors, as will be discussed in the following sections.

\section{Obesity and GCA}

Eleven studies have been published on the relationship between BMI and the incidence of GCA (Table 1). There is considerable methodological heterogeneity among these reports regarding the definition of GCA, study design (case-control vs cohort), the confounding variables entered into the analyses (e.g., most included smoking, none included $H$. pylori infection), the time interval between BMI assessment and cancer outcome, and the definition of BMI category. Only two of these reports were of Asian populations (both in China), with others from the USA and northwestern Europe. Nevertheless, nine of the 11 studies did demonstrate a positive association between increased BMI and GCA risk, with many of them describing a positive dose-response relationship.

The earliest report of BMI and GCA was a case-control study conducted by Ji et al. [21] in 1997 that evaluated 185 cases of GCA diagnosed between 1988 and 1989 in Shanghai, China. Overall the OR was 3.0 (95\% CI 1.7-5.4) among men in the fourth (highest) quartile of BMI compared with the first quartile. No BMI trend was found in the small number of cases among the women. The following year, Chow et al. [22] reported on a total of 292 cases in a similarly designed study from three states in the USA. Although GCA was not precisely defined in that publication, Chow et al. described a statistically significant trend for GCA risk across the BMI quartiles, for men and women combined. These studies confirmed that, early in the obesity epidemic, there was an empirical suggestion of a correlation between BMI and GCA incidence.

Framing a definition to calculate relative risk among obese and nonobese study participants has had methodological variability, with some authors choosing to calculate relative risk among study participants, and others opting to stratify BMI from predefined categories. Lagergren et al. [23] calculated odds ratios (ORs) using both methods, reporting statistical significance for each [OR 2.3, $95 \%$ confidence interval (CI) 1.5-3.6, for fourth quartile vs first quartile and OR 4.3, $95 \%$ CI 2.1-8.7, for BMI $>30 \mathrm{~kg} / \mathrm{m}^{2}$ vs BMI $<22 \mathrm{~kg} / \mathrm{m}^{2}$ ]. Nevertheless, the comparator group in each analysis was the thinnest patients, rather than normal-weight patients. Several other studies calculated 
Table 1 Summary of studies on body mass index $(B M I)$ and gastric cardia adenocarcinoma

\begin{tabular}{|c|c|c|c|c|c|c|}
\hline Study & Population & Cardia definition & Design & $\begin{array}{l}\text { Number } \\
\text { of cases }\end{array}$ & Main findings & $\begin{array}{l}P \text { for } \\
\text { trend? }\end{array}$ \\
\hline Ji et al. [21] & China & $\mathrm{C} 16.0$ & $\mathrm{C}-\mathrm{C}$ & 185 & $\begin{array}{l}\text { Q4 vs Q1 RR 3.0 (95\% CI 1.7-5.4) for men, } 1.4 \\
\text { (95\% CI 0.5-4.1) for women }\end{array}$ & Yes \\
\hline Chow et al. [22] & USA & ND & $\mathrm{C}-\mathrm{C}$ & 261 & Q4 vs Q1 RR 1.6.(95 \% CI 1.1-2.6) & Yes \\
\hline Lagergren et al. [23] & Sweden & $\begin{array}{l}2 \mathrm{~cm} \text { proximal, } 3 \mathrm{~cm} \\
\text { distal to GEJ without } \\
\text { Barrett's esophagus }\end{array}$ & $\mathrm{C}-\mathrm{C}$ & 262 & $\begin{array}{l}\text { Q4 vs Q1 RR } 2.3 \text { (95\% CI } 1.5-3.6) \text { for } \\
\text { BMI }>30 \mathrm{~kg} / \mathrm{m}^{2} \text { (obese) vs } 4.3(95 \% \text { CI } \\
2.1-8.7) \text { for BMI }<22 \mathrm{~kg} / \mathrm{m}^{2}\end{array}$ & Yes \\
\hline Wu et al. [30] & USA & $\mathrm{C} 16.0$ & $\mathrm{C}-\mathrm{C}$ & 277 & $\begin{array}{l}\text { Q4 vs Q1 RR 1.8, irrespective of when BMI } \\
\text { measured (current, age } 20 \text { years, or age } 40 \text { years) }\end{array}$ & Yes \\
\hline Tran [24] & China & ND & Cohort & 1,089 & $\begin{array}{l}\text { No association. Complicated study design } \\
\text { including diet intervention }\end{array}$ & No \\
\hline Lindblad [25] & UK & ND & $\mathrm{C}-\mathrm{C}$ & 195 & $\begin{array}{l}\mathrm{BMI}>30 \mathrm{~kg} / \mathrm{m}^{2} \mathrm{RR} 1.46(95 \% \text { CI } 0.84-2.54) \mathrm{vs} \\
\text { reference }\left(\mathrm{BMI} 20-24 \mathrm{~kg} / \mathrm{m}^{2}\right) . \text { BMI } 25-29 \mathrm{~kg} / \mathrm{m}^{2} \\
\text { RR } 1.37(95 \% \text { CI } 0.89-2.1) \text { vs reference }\end{array}$ & Yes \\
\hline Samanic et al. [26] & Sweden & $\mathrm{C} 16.0$ & Cohort & 108 & No association & No \\
\hline Merry et al. [27] & Netherlands & $\mathrm{C} 16.0$ & Cohort & 173 & $\begin{array}{l}\text { BMI }>30 \mathrm{~kg} / \mathrm{m}^{2} \mathrm{RR} 2.73(95 \% \text { CI } 1.56-4.79) \text { vs } \\
\text { normal BMI }\left(20-25 \mathrm{~kg} / \mathrm{m}^{2}\right) . \text { Also BMI increase } \\
\text { over time associated with cardia cancer risk } \\
(2.07,95 \% \text { CI } 1.08-3.97)\end{array}$ & Yes \\
\hline Ryan et al. [31] & Ireland & Siewert type 3 & $\mathrm{C}-\mathrm{C}$ & 64 & $\begin{array}{l}\mathrm{BMI}>30 \mathrm{~kg} / \mathrm{m}^{2} \text { vs } \mathrm{BMI}<22 \mathrm{~kg} / \mathrm{m}^{2}, \mathrm{RR} 2.7 \\
\quad(95 \% \text { CI } 0.9-8.0)\end{array}$ & $\mathrm{N}$ \\
\hline Corley et al. [28] & USA & $\mathrm{C} 16.0$ & $\mathrm{C}-\mathrm{C}$ & 105 & $\begin{array}{l}\mathrm{BMI}>30 \mathrm{~kg} / \mathrm{m}^{2} \mathrm{RR} 2.04(95 \% \text { CI } 0.99-4.21) \mathrm{vs} \\
\quad \text { BMI } 18.5-25 \mathrm{~kg} / \mathrm{m}^{2}\end{array}$ & $?$ \\
\hline Abnet et al. [29] & USA & & Cohort & 307 & $\begin{array}{l}\text { BMI 30-35, RR } 1.70(95 \% \text { CI } 1.22-2.36) \\
\left.\text { BMI }>35 \mathrm{~kg} / \mathrm{m}^{2} \text { RR } 2.40 \text { (95 \% CI } 1.60-3.80\right) \\
\text { vs BMI } 18.5-25 \mathrm{~kg} / \mathrm{m}^{2}\end{array}$ & Yes \\
\hline
\end{tabular}

C16.0 refers to the International Classification of Diseases for Oncology (ICD-O) code C16.0.

$B M I$ body mass index, $C-C$ case-control, $C I$ confidence interval, $G E J$ gastroesophageal junction, $N D$ not defined, $Q 1$ first quartile, $Q 4$ fourth quartile, $R R$ relative risk

ORs based on a referent of BMI-defined normal, thus excluding the leanest subgroup of patients [23-29].

The largest study in the USA drew from data in the US NIH-AARP registry, a cohort of 480,475 patients across six US states between 1995 and 1996, in which 307 incident cases of GCA have been reported after about 20 years [29]. The study authors defined GCA using the standard ICD-O C16.0 definition and analyzed their results using WHO-defined criteria of normal BMI $\left(18.5 \mathrm{~kg} / \mathrm{m}^{2}\right.$ to less than $25 \mathrm{~kg} / \mathrm{m}^{2}$ ) for reference. They found that obese (BMI from $30 \mathrm{~kg} / \mathrm{m}^{2}$ to less than $35 \mathrm{~kg} / \mathrm{m}^{2}$ ) and morbidly obese $\left(\mathrm{BMI}>35 \mathrm{~kg} / \mathrm{m}^{2}\right.$ ) patients had 84 and $269 \%$ (both statistically significant) elevated risk of GCA incidence (OR $2.69,95 \%$ CI 1.77-4.09). The trend, using standardized BMI categories, has been confirmed in other US studies. For example, Corley et al. [28] compared normal BMI and obese patients in a case-control study of 105 GCA cases. The results were broadly similar to those of Abnet et al. [29], with an OR of 2.04 (95\% CI 0.99-4.21) for obese individuals. Merry et al. [27] evaluated 173 patients in a cohort population from the Netherlands, reporting an even stronger and statistically significant correlation of obesity with WHO-defined normal BMI, with an OR of 2.73. This was the only study that also calculated ORs for BMI change since age 20 years, reporting an OR of 2.07 (95\% CI 1.08-3.97).

Among the 11 studies in Table 1, only two did not report a statistically significant relationship between BMI and GCA risk $[24,26]$. The very large study of 1,089 cases by Tran [24] was also complicated by a dietary supplement intervention, making interpretation of the results problematic. Samanic et al. [26] reported on multiple cancer subtypes in a Swedish cohort population of 389,000 individuals, including only $5 \%$ women. In that study of 108 incident cases of ICD-O-defined GCA, there was no correlation with BMI, in contrast to another study from Sweden [23].

It is noteworthy that of the ten publications in Table 1 that also addressed distal gastric cancer concurrently, nine found no correlation between BMI and distal gastric cancer. Despite the methodological heterogeneity, the absence of statistical significance seems to be 
consistent. The study of Wu et al. [30] was the only one to find a borderline correlation with distal gastric cancer, for 443 patients $(1.43,95 \%$ CI 1.0-2.1) when looking at the fourth quartile at age 20 years (compared with low BMI in the first quartile). However, the study was limited by a changing definition of GCA and some cases that were reclassified as noncardia tumors, thus skewing the correlation.

There were nine studies of GCA that also included epidemiological data on EAC in the same cohort or population [22-26, 28-31], showing a generally stronger link between EAC and BMI than between GCA and BMI [22, 24, 26, 29, 31]. In general, this meant both higher calculated ORs and a higher degree of statistical certainty for the obese and the overweight when compared with normal-weight individuals. For example, Chow et al. [22] found ORs in the third and fourth quartiles of 2.0 and 3.0 (both significant) for EAC, whereas they found an OR of only 1.8 for the fourth quartile for GCA. These results are overall consistent with the meta-analysis of the relationship between overweight/obesity and EAC and GCA by Turati et al. [32]. In that report, obesity (BMI $>30 \mathrm{~kg} / \mathrm{m}^{2}$ ) was associated with a relative risk of 2.73 (95\% CI 2.16-3.46) for EAC, but only 1.93 (95\% CI 1.52-2.45) for GCA. Similarly, overweight (BMI $25-30 \mathrm{~kg} / \mathrm{m}^{2}$ ) was associated with a relative risk of 1.87 (95\% CI 1.61-2.17) for EAC but only 1.40 (95\% CI 1.18-1.66) for GCA. However, as discussed previously, these summary statistics by Turati et al. do include considerable study design heterogeneity and variable cancer site definitions. And the picture becomes even more skewed as, over time, the pathological definitions of GCA have evolved and varied between studies.

Finally, it is appreciated that the BMI (as defined by either WHO criteria or study-set quartiles) is only one way to measure obesity. Two studies have evaluated alternative anthropometric methods [28, 32]. Corley et al. [28] measured anterior-posterior diameter (a marker for central adiposity) and did not find any statistical significance with GCA, but did with EAC for a diameter of more than $25 \mathrm{~cm}$ versus a diameter of less than $20 \mathrm{~cm}$ (OR 3.47, $95 \%$ CI 1.29-9.33). O'Doherty et al. [33] evaluated another metric, waist-to-hip-ratio, in 191 cases of GCA and 253 cases of EAC, reporting statistical significance with the fourth quartile (vs the first quartile) for GCA (OR 2.22, $95 \%$ CI 1.43-3.47) and for the third quartile and the fourth quartile for EAC (ORs 1.51 and 2.01, respectively). These alternative methods of measuring obesity serve to confirm the use of BMI as a metric to measure incident cancer risk epidemiologically.

\section{Obesity-related risk factors in GCA}

Gastroesophageal reflux disease

Unlike the clear association between EAC and reflux disease $[34,35]$, data regarding the presence of GERD in patients with GCA has been less strong or even absent, with most studies finding evidence for an association [16, $34,35]$ and others not [36]. In a population of 53 cases of GCA, a study found an OR of 10.0 (95\% CI 2.2-44.3) for the development of GCA with GERD symptoms more than two times per week, compared with age-matched controls [16]. Only $7.5 \%$ of control subjects had frequent symptoms, compared with $26.4 \%$ of incident GCA cases. However, a case-control study of 261 patients by Engel et al. [36] found no association between GCA and GERD symptoms. The data remain mixed on this topic of reflux symptoms and predisposition toward GCA. They are also limited by analyses performed after the diagnosis of GCA had been established in the cases, retrospectively looking at GERD-related symptoms with inevitable recall bias.

\section{Acid-suppressing medication use}

The widespread use of acid-suppressing medications started in the 1970s, initially with histamine $\mathrm{H}_{2}$ receptor antagonists, followed by the more potent proton pump inhibitors. This was around the time when GCA and EAC rates began to rise. The only large case-control study of the use of these medications with GCA specifically was within the UK General Practitioner Database, in which 195 GCA cases were identified [37]. Excluding patients who were current users of acid-suppressing medications at the time of the cancer diagnosis (to rule out confounding by symptoms), past users of proton pump inhibitors had an increased risk of GCA development in that study of nearly 2 , which was marginally statistically significant. The association with $\mathrm{H}_{2}$ receptor antagonists was less marked. A drawback of the study was that the diagnosis of GCA was not clearly defined. Additionally, the data on prescription use was based on the prescription being written rather than necessarily filled. Nevertheless, the results are provocative and consistent with another study [38] showing a weak association between acid-suppressing medication use and total number of gastric cancer cases, not broken down by anatomical subsite. A mechanistic link between the use of these medications and gastric carcinogenesis is conceivable, on the basis of the moderately elevated gastrin levels frequently found in users of these drugs and the trophic (proproliferative) effects of gastrin on the gastrointestinal mucosa [39]. 


\section{Diabetes mellitus}

In the face of the evidence linking obesity and adiposity with the prevalence of GCA, it is important to examine the role of DM as a possible confounder in this relationship. In general, for gastric cancer, when all subtypes are considered together, there is a large body of evidence suggesting a weak association of DM with gastric cancer (overall OR about 1.1-1.2), which is especially skewed toward females and Southeast Asians [40]. Three case-control studies have addressed specifically the relationship between DM and gastric GCA using case-control designs [41-43]. Two were from the USA [42, 43] and one was from Australia [41], and all used the standard GCA Siewert type 2/3 definition, with DM being self-reported in each study. Only one of the studies reported a significant association between DM and GCA, suggesting that the relationship between obesity and GCA is unlikely to be due entirely to the prevalence of DM.

\section{Diet}

In light of the trend of GCA prevalence with obesity, the role of specific dietary components is also a valid research question. The positive effect of a diet based on fruits and vegetables has been analyzed in several studies [44, 45]. In a meta-analysis by Stevens et al. [44], several significant trends were noted. Increased consumption of cruciferous vegetables was associated with a reduced risk of GCA, with a relative risk of 0.72 (95\% CI 0.54-0.95). In addition, fruit intake (notably citrus fruits) was associated with a significant reduction in GCA risk, with the exception of the lowest quartile of consumption. Lunet et al. [45] reported similar findings in a population-based case-control design and formalized review of the literature through a meta-analysis, concluding that when comparing the highest with the lowest quartile of fruit consumption the relative risk of GCA was 0.53 (95\% CI 0.35-0.80), with similar benefits from vegetable intake (relative risk 0.63 , $95 \%$ CI 0.50-0.70). However, other studies have not always confirmed a protective effect from increased vegetable and/or fruit consumption. In a case-control study by Terry et al. [46], no protective effect was noted for fruit and vegetable consumption in a Swedish population of 262 cases of incident GCA. Other components of the diet may have deleterious effects. Navarro et al. [47] reported that both meat and dairy intake were associated with a significantly elevated risk of GCA (OR 1.37, $95 \%$ CI 1.08-1.73, and OR 1.23, $95 \%$ CI 1.01-1.51, respectively). In that same study, grain was also found to elevate risk (OR 1.29, $95 \%$ CI 1.08-1.53).

In general, the findings of most of these dietary studies are consistent with a beneficial effect of fruits and vegetables and a deleterious effect from diets high in red meats and fat [48], consistent with the findings of most dietary studies of cancer risk. However, case-control studies are prone to considerable recall bias. For example, coefficients of differences in nutrient intake can vary between participants and observers by between 4 and $400 \%$ in a $24-\mathrm{h}$ period. In addition, there is a potential for subjects to both overreport and underreport [49]. Although some of the studies include adjustments for BMI, very few of them take into account H. pylori status.

\section{Helicobacter pylori}

H. pylori has been an almost universal inhabitant of the human stomach, from the emergence of Homo sapiens until the last couple of decades. Its recent disappearance in the developed world has been accompanied by changes in gastric acid physiology, peptide secretion, regulatory $\mathrm{T}$ cell populations, and even the production of the satiety peptide ghrelin [50]. Is it possible that the decline in $H$. pylori prevalence is somehow linked with the rise in obesity and the prevalence of gastric GCA?

The strong positive association between infection with H. pylori and distal gastric cancer is well established, but its relationship with GCA has been less extensively evaluated. Overall the relative risk of GCA in $H$. pylori infected subjects is about $0.5-1$ in most studies [51], suggesting that, as for EAC, H. pylori likely exerts a protective effect, if any, on GCA incidence [51-53]. It is noteworthy that this inverse relationship between $H$. pylori infection and GCA does not seem to be due to the inclusion only of studies from Western populations, nor is there a consistent difference according to whether or not the infecting $H$. pylori strain is positive for CagA, a putative bacterial oncoprotein [51, 52, 54].

Is it possible that the positive association between obesity and GCA is due to the absence of $H$. pylori somehow preventing obesity? In the developing world, $H$. pylori infection is associated with small stature, growth impairment, malnutrition, and iron deficiency [55, 56]. However, $H$. pylori itself may not necessarily be responsible for this growth impairment, but could just be a marker of poor socioeconomic status. Cross-sectional studies from the USA performed as part of the third National Health and Nutrition Examination Survey failed to show a relationship between BMI and $H$. pylori seroprevalence $[57,58]$. Nevertheless, the idea that $H$. pylori can protect against obesity is supported by the largest randomized placebo-controlled trial of $H$. pylori eradication in dyspeptic patients, which was conducted in the UK [59]. With over 700 patients in each arm, there was significantly more weight gain in those subjects in whom $H$. pylori was eradicated at the 6-month follow-up, compared with those subjects who were 
persistently infected. The study authors attributed this weight gain to possible resolution of dyspepsia, although it is conceivable that it was instead due to H. pylori eradication influencing gastric pathophysiology in the direction of increased satiation. Indeed, $H$. pylori does have an effect on ghrelin secretion from specialized gastric $\mathrm{P} / \mathrm{D}_{1}$ neuroendocrine cells [60]. Ghrelin has anti-inflammatory effects, and plasma levels are relatively low in obese patients, but the consequences of decreased ghrelin secretion have not been studied extensively, especially in the context of $H$. pylori infection. Ghrelin metabolism and posttranslational modification by octanoylation altering biological activity is complex, but since there is overall some weak evidence that H. pylori may influence (prevent) obesity, this area is worthy of further study.

\section{Atrophic gastritis}

Atrophic gastritis, characterized by loss of glandular and parietal cells and subsequent replacement by intestinal metaplasia and interstitial fibrosis [61], is typically associated with $H$. pylori infection, or, less commonly, results from autoimmune gastritis. Its presence can be detected directly by gastric biopsy or indirectly via serologic detection of pepsinogen levels. When there is loss of the glandular stomach cells that uniquely produce pepsinogen I, pepsinogen I levels decrease, whereas the level of pepsinogen II, secreted by cells in the fundus, antrum, and duodenum, tends to remain stable; thus the ratio of pepsinogen I to pepsinogen II can be used as an indirect marker of gastric atrophy. Several studies have explored the relationship between atrophic gastritis and GCA. In a meta-analysis by Islami et al. [62], the 13 studies included were relatively homogeneous, with an overall risk ratio for atrophy with GCA of 2.89 (95\% CI 2.09-3.98). This increased risk was upheld in subgroup analyses by study geographic location, large studies, studies with adjusted results, and in all cases, regardless of how atrophy was evaluated. The positive association of atrophic gastritis with GCA is in contrast to that between atrophy and EAC [62] and is difficult to explain on the basis of the lack of a positive association between GCA and $H$. pylori infection, the commonest cause of atrophic gastritis worldwide.

\section{Possible mechanisms linking obesity with GCA}

Obesity is a risk factor for many types of malignancy, and there are multiple mechanisms linking obesity to the promotion of gastrointestinal carcinogenesis in general [63]. The biochemical mechanisms linking obesity to cancer include hyperinsulinemia, increased levels of insulin-like growth factors (IGFs), and altered IGF/IGF-binding protein ratios that promote cell division and inhibit apoptosis [63]. IGF-1 receptors are found throughout the gastrointestinal tract, especially in the gastric mucosa. Growth factors emitted from adipocytes, so-called adipokines, include leptin and adiponectin. On the one hand, leptin participates in the cellular growth cascade, inhibiting apoptosis and promoting cell proliferation and angiogenesis, whereas adiponectin, expressed in differentiated adipocytes, opposes proliferation and angiogenesis, has anti-inflammatory properties, and its level is usually decreased in obesity [63]. The adiponectin level has been reported to be lower in patients with GCA than in control subjects [64, 65]. A subclinical state of increased inflammation is common in obesity, perhaps driven by changes in the intestinal microbiome [63].

The mechanisms by which these risk factors contribute to GCA carcinogenesis specifically has been little studied, except for in relationship to gastroesophageal reflux. Mechanical forces, altered by increased adiposity, can lead to elevations in intra-abdominal pressure applied to the lower esophageal sphincter. Elevated intra-abdominal pressure has been thought to predispose toward upward flow of gastric content. The predisposition to GERD from altered pressures, in turn, may predispose to carcinogenesis at the gastroesophageal junction. However, because GERD is more tightly linked to EAC than to GCA, most prior mechanistic research focused on the contribution of excessive gastric reflux to esophageal carcinogenesis. As discussed earlier, GCA may be part of the same spectrum of disease as EAC, at least in the West.

In this respect, recent findings on events at the cardia in reflux may be relevant to the pathogenesis of both EAC and GCA. Of particular interest is the report by Robertson et al. [66], who evaluated a group of 51 middle-aged subjects without a hiatal hernia or $\mathrm{H}$. pylori infection to determine correlations between obesity, as determined by waist size and abdominal magnetic resonance imaging, and cardiac mucosal length, inflammation of the distal lower esophageal sphincter scored pathologically, $\mathrm{pH}$, and other measurements of gastroesophageal function. In that study, inflammatory cells were found to be present in the cardia in all cases, irrespective of BMI, but the obese subjects had more proximal acid reflux and a longer cardia length ( $2.5 \mathrm{~mm}$ vs $1.75 \mathrm{~mm}$ in the normal BMI cases, $p=0.008$ ). Conceivably, this lengthening may encourage the expansion and outward migration of cardia progenitor cells into the gastroesophageal junction, thereby promoting gastroesophageal junction neoplasia [67].

Since some patients treated for GERD fail to respond to acid-suppressing therapy, there has been interest in the contribution of nonacidic gastric contents to the development of GERD and its complications. Potentially important components of this refluxate are bile acids, including cholic 
acid, chenodeoxycholic acid, and the secondarily dehydroxylated deoxycholic acid [68]. Bile acids may be especially relevant in the origin of gastroesophageal junction cancers, since they have recently been shown to also induce signaling pathways with metabolic consequences $[69,70]$.

The data on the effects of bile acids on the cardia are limited. One case-control study evaluated 192 patients without $H$. pylori infection, reporting an association between metaplasia and excessive bile reflux that did not reach statistical significance [71]. Another group of investigators evaluated 66 patients undergoing gastroscopy for heartburn or regurgitation, reporting no correlation between proximal stomach bile acid exposure and the severity of carditis or esophagitis [72]. Thus, the effects of bile on the gastric cardia are uncertain, and further studies on the role of bile acid reflux in cardia cancer are warranted.

\section{Conclusions}

Over the past 30 years, two epidemiological trends of obesity and of an increase in GCA prevalence and lower EAC prevalence have moved almost in parallel. For GCA, the link with obesity is clear, although it is not as strong a risk factor for GCA development as it is for EAC development. Nevertheless, the epidemiology of GCA is much closer to that EAC than it is for distal gastric cancers. Although there are major issues with the definition of GCA and even some debate concerning whether GCAs are truly a distinct entity [20], the association of GCA with obesity that we have reviewed deserves further investigation, especially outside the USA and northwestern Europe, where almost all epidemiological association studies have been conducted thus far.

Further exploration of the mechanisms linking obesity to the promotion of GCA development is also important because this might identify factors amenable to modification. Most current evidence points to reflux, mechanical forces of elevated intra-abdominal pressure, diet, and/or endocrinological mechanisms as risk factors for both EAC and GCA, but more detailed analysis including attention to the site of origin of GCA may be of value in defining whether there is a unique pathogenic pathway for GCA carcinogenesis.

\section{References}

1. Roder DM. The epidemiology of gastric cancer. Gastric Cancer. 2002;5(Suppl 1):5-11.
2. Anderson W, Camargo MC, Fraumeni JF, Correa P, Rosenberg PS, Rabkin CS. Age-specific trends in incidence of noncardia gastric cancer in US adults. JAMA. 2010;303:1723-8.

3. Dubecz A, Solymosi N, Stadlhuber RJ, Schweigert M, Stein HJ, Peters JH. Does the incidence of adenocarcinoma of the esophagus and gastric cardia continue to rise in the twenty-first century? - a SEER database analysis. J Gastrointest Surg. 2013;18: 124-9.

4. American Cancer Society Cancer. Facts \& figures 2013. American Cancer Society. 2013. http://www.cancer.org/acs/groups/ content/@epidemiologysurveilance/documents/document/acspc036845.pdf. Accessed 13 May 2014.

5. Fock KM. Review Article: the epidemiology and prevention of gastric cancer. Aliment Pharmacol Ther. 2014;40:250-60.

6. Rahman R, Asombang AW, Ibdah JA. Characteristics of gastric cancer in Asia. World J Gastroenterol. 2014;20:4483-90.

7. Deans C, Yeo MSW, Soe MY, Shabbir A, Ti TK, So JBY. Cancer of the gastric cardia is rising in incidence in an Asian population and is associated with adverse outcome. World J Surg. 2011;35:617-24.

8. Turner JR. The gastrointestinal tract. In: Kumar V, Abbas AK, Fausto N, Aster JC, editors. Robbins and Cotran pathologic basis of disease. 8th ed. Philadelphia: Saunders; 2010. p. 763-831.

9. Chandrasoma PT, Lokuhetty DM, Demeester TR, Bremmer CG, Peters JH, Oberg S, et al. Definition of histopathologic changes in gastroesophageal reflux disease. Am J Surg Pathol. 2000;24: 344-51.

10. Kilgore SP, Ormsby AH, Gramlich TL, Rice TW, Richter JE, Falk GW, et al. The gastric cardia: fact or fiction? Am J Gastroenterol. 2000;95:921-4.

11. Glickman JN Fox, Fox V, Antonioli DA, Wang HH, Odze RD. Morphology of the cardia and significance of carditis in pediatric patients. Am J Surg Pathol. 2002;26:1032-9.

12. Hertogh GD, Van Eyken P, Ectors N, Tack J, Geboes K. On the existence and location of cardiac mucosa: an autopsy study in embryos, fetuses, and infants. Gut. 2003;52:791-6.

13. McColl KE. Cancer of the gastric cardia. Best Pract Res Clin Gastroenterol. 2006;20:687-96.

14. Mariette C. Oesophagogastric junction adenocarcinoma: which therapeutic approach? Lancet Oncol. 2011;12:296-305.

15. Edge SB. AJCC cancer staging handbook: from the AJCC cancer staging manual. 7th ed. New York: Springer; 2010.

16. Derakhshan MH, Malekzadeh R, Watabe H, Yazdanbod A, Fyfe $\mathrm{V}$, Kazemi A, et al. Combination of gastric atrophy, reflux symptoms and histological subtype indicates two distinct aetiologies of gastric cardia cancer. Gut. 2008;57:298-305.

17. Wijetunge S, Ma Y, DeMeester S, Hagen J, Demeester $T$, Chandrosoma P. Association of adenocarcinomas of the distal esophagus, gastroesophageal junction, and gastric cardia with gastric pathology. Am J Surg Pathol. 2010;32:1521-7.

18. Oh DS, Demeester SR, Tanaka K, Marjoram P, Kuramochi H, Vallbohmer D, et al. The gene expression profile of cardia intestinal metaplasia is similar to that of Barrett's esophagus, not gastric intestinal metaplasia. Dis Esophagus. 2011;24:516-22.

19. Huang Q. Carcinoma of the gastroesophageal junction in Chinese patients. World J Gastroenterol. 2012;18:7134-40.

20. McColl KEL, Going JJ. Aetiology and classification of adenocarcinoma of the gastro-oesophageal junction/cardia. Gut. 2010;59:282-4.

21. Ji BT, Chow WH, Yang G, McLaughlin JK, Gao RN, Zheng W, et al. Body mass index and the risk of cancers of the gastric cardia and distal stomach in Shanghai, China. Cancer Epidemiol Biomarkers Prev. 1997;6:481-5.

22. Chow WH, Blot WJ, Vaughan TL, Risch HA, Gammon MD, Stanford JL, et al. Body mass index and risk of adenocarcinomas 
of the esophagus and gastric cardia. J Natl Cancer Inst. 1998; $90: 150-5$.

23. Lagergren J, Bergström R, Olof N. Association between body mass and adenocarcinoma of the esophagus and gastric cardia. Ann Intern Med. 1999;130:883-90.

24. Tran GD. Prospective study of risk factors for esophageal and gastric cancers in the Linxian general population trial cohort in China. J Cancer. 2005;113:456-63.

25. Lindblad M, Rodríguez LA, Lagergren J. Body mass, tobacco and alcohol and risk of esophageal, gastric cardia, and gastric noncardia adenocarcinoma among men and women in a nested casecontrol study. Cancer Causes Control. 2005;16:285-94.

26. Samanic C, Chow WH, Gridley G, Jarvholm B, Fraumeni JF. Relation of body mass index to cancer risk in 362,552 Swedish men. Cancer Causes Control. 2006;17:901-9.

27. Merry AHH, Schouten LJ, Goldbohm RA, van den Brandt PA. Body mass index, height and risk of adenocarcinoma of the oesophagus and gastric cardia: a prospective cohort study. Gut. 2007;56:1503-11.

28. Corley DA, Kubo A, Zhao W. Abdominal obesity and the risk of esophageal and gastric cardia carcinomas. Cancer Epidemiol Biomarkers Prev. 2008;17:352-8.

29. Abnet CC, Freedman ND, Hollenbeck AR, Fraumeni JF Jr, Leitzmann M, Schatzkin A. A prospective study of BMI and risk of oesophageal and gastric adenocarcinoma. Eur $\mathrm{J}$ Cancer. 2008;44:465-71.

30. Wu AH, Wan P, Bernstein L. A multiethnic population-based study of smoking, alcohol and body size and risk of adenocarcinomas of the stomach and esophagus (United States). Cancer Causes Control. 2001;12:721-32.

31. Ryan AM, Rowley SP, Fitzgerald AP, Ravi N, Reynolds JV. Adenocarcinoma of the oesophagus and gastric cardia: male preponderance in association with obesity. Eur $\mathrm{J}$ Cancer. 2006;42:1151-8.

32. Turati F, Tramacere I, La Vecchia C, Negri E. A meta-analysis of body mass index and esophageal and gastric cardia adenocarcinoma. Ann Oncol. 2013;24:609-17.

33. O’Doherty MG, Freedman ND, Hollenbeck AR, Schatzkin A, Abnet CC. A prospective cohort study of obesity and risk of oesophageal and gastric adenocarcinoma in the NIH-AARP diet and health study. Gut. 2012;61:1261-8.

34. Lagergren J, Bergstrom R, Lindgren A, Nyren O. Symptomatic gastroesophageal reflux as a risk factor for esophageal adenocarcinoma. N Engl J Med. 1999;340:825-31.

35. Wu AH, Tseng CC, Bernstein L. Hiatal hernia, reflux symptoms, body size, and risk of esophageal and gastric adenocarcinoma. Cancer. 2003;98:940-8.

36. Engel LS, Chow WH, Vaughan TL, Gammon MD, Risch HA, Stanford JL, et al. Population attributable risks of esophageal and gastric cancers. J Natl Cancer Inst. 2003;95:1404-13.

37. Garcia Rodriguez LA, Lagergren J, Lindblad M. Gastric acid suppression and risk of oesophageal and gastric adenocarcinoma: a nested case control study in the UK. Gut. 2006;55:1538-44.

38. Poulsen AH, Christensen S, McLaughlin JK, Thomsen RW, Sørensen HT, Olsen JH, et al. Proton pump inhibitors and risk of gastric cancer: a population-based cohort study. Br J Cancer. 2009;100:1503-7.

39. Dimaline R, Varro A. Novel roles of gastrin. J Physiol. 2014;592:2951-8.

40. Tseng CH, Tseng FH. Diabetes and gastric cancer: the potential links. World J Gastroenterol. 2014;20:1701.

41. Neale RE, Doecke JD, Pandeya N, Sadeghi S, Green AC, Webb $\mathrm{PM}$, et al. Does type 2 diabetes mellitus influence the risk of oesophageal adenocarcinoma? Br J Cancer. 2009;100:1514.

42. Lin SW, Freedman ND, Hollenbeck AR, Schatzkin A, Abnet CC. Prospective study of self-reported diabetes and risk of upper gastrointestinal cancers. Cancer Epidemiol Biomarkers Prev. 2011;20:954-61.

43. Jiang X, Bernstein L, Tseng CC, Wu AH. Diabetes and risk of esophageal and gastric adenocarcinomas. Int $\mathrm{J}$ Cancer. 2012;131:1417-22.

44. Stevens J, Schouten LJ, Goldbohm RA, van den Brandt PA. Vegetables and fruits consumption and risk of esophageal and gastric cancer subtypes in the Netherlands cohort study. Int $\mathbf{J}$ Cancer. 2011;129:2681-93.

45. Lunet N, Valbuena C, Vieira AL, Lopes C, Lopes C, David L, et al. Fruit and vegetable consumption and gastric cancer by location and histological type: case-control and meta-analysis. Eur J Cancer Prev. 2007;16:312-27.

46. Terry P, Hansen H, Wolk A, Nyrén O. Fruit and vegetable consumption in the prevention of oesophageal and cardia cancer. Eur J Cancer Prev. 2001;10:365-9.

47. Navarro S, Stephanie A, Mayne ST, Risch H, Gammon MD, Vaughan TL, et al. Food group intake and risk of subtypes of esophageal and gastric cancer. Int J Cancer. 2008;123:852-60.

48. Bertuccio P, Rosato V, Andreano A, Ferraroni M, Decarli A, Edefonti $\mathrm{V}$, et al. Dietary patterns and gastric cancer risk: a systematic review and meta-analysis. Ann Oncol. 2013;24: 1450-8.

49. Bingham SA. Limitations of the various methods for collecting dietary intake data. Ann Nutr Metab. 1991;35:117-27.

50. Blaser MJ, Chen Y, Reibman J. Does Helicobacter pylori protect against asthma and allergy? Gut. 2008;57:561-7.

51. IARC Working Group on the Evaluation of Carcinogenic Risks to Humans. A review of human carcinogens: biological agents. Vol. 100. Geneva: WHO Press; 2009.

52. Kamangar F, Dawsey SM, Blaser MJ. Opposing risks of gastric cardia and noncardia gastric adenocarcinomas associated with Helicobacter pylori seropositivity. J Natl Cancer Inst. 2006;98: 1445-52.

53. Islami F, Kamangar F. Helicobacter pylori and esophageal cancer risk: a meta-analysis. Cancer Prev Res. 2008;1:329-38.

54. Chow WH, Blaser MJ, Blot WJ, Gammon MD, Vaughan TL, Risch HA, et al. An inverse relation between cagA+ strains of Helicobacter pylori infection and risk of esophageal and gastric cardia adenocarcinoma. Cancer Res. 1998;58:588-90.

55. Queiroz DMM, Rocha AMC, Crabtree JE. Unintended consequences of Helicobacter pylori infection in children in developing countries: iron deficiency, diarrhea and growth retardation. Gut Microbes. 2013;4:42-3.

56. Mera RM, Correa P, Fontham EE, Reina JC, Pradilla A, Alzate A, et al. Effects of a new Helicobacter pylori infection on height and weight in Colombian children. Ann Epidemiol. 2006;16:347.

57. Ioannou GN, Weiss NS, Kearney DJ. Is Helicobacter pylori seropositivity related to body mass index in the United States? Aliment Pharmacol Ther. 2005;21:765-72.

58. Cho I, Blaser MJ, François F, Mathew JP, Ye XY, Goldberg JD, et al. Helicobacter pylori and overweight status in the United States: data from the Third National Health and Nutrition Examination Survey. Am J Epidemiol. 2005;162:579-84.

59. Lane JA, Murray LJ, Harvey IM, Donovan JL, Nair P, Harvey RF. Randomised clinical trial: Helicobacter pylori eradication is associated with a significantly increased body mass index in a placebocontrolled study. Aliment Pharmacol Ther. 2011;33:922-9.

60. Jeffery PL, McGuckin MA, Linden SK. Endocrine impact of Helicobacter pylori: focus on ghrelin and ghrelin O-acyltransferase. World J Gastroenterol. 2011;17:1249.

61. Rugge M, Correa P, Di Mario F, El-Omar E, Fiocca R, Geboes K, et al. OLGA staging for gastritis: a tutorial. Dig Liver Dis. 2008;40:650-8.

62. Islami F, Sheikhattari P, Ren JS, Kamangar F. Gastric atrophy and risk of oesophageal cancer and gastric cardia 
adenocarcinoma-a systematic review and meta-analysis. Ann Oncol. 2011;22:754-60.

63. Alemán JO, Eusebi LH, Ricciardiello L, Patidar K, Sanyal AJ, Holt PR. Mechanisms of obesity-induced gastrointestinal neoplasia. Gastroenterology. 2014;146:357-73.

64. Nakajima TE, Yamada Y, Hamano T, Furuta K, Gotoda T, Katai $\mathrm{H}$, et al. Adipocytokine levels in gastric cancer patients: resistin and visfatin as biomarkers of gastric cancer. J Gastroenterol. 2009;44:685-90.

65. Ishikawa M, Kitayama J, Kazama S, Hiramatsu T, Hatano K, Nagawa H. Plasma adiponectin and gastric cancer. Clin Cancer Res. 2005;11:466-72.

66. Robertson EV, Derakhshan MH, Wirz AA, Lee YY, Seenan JP, Ballantyne SA, et al. Central obesity in asymptomatic volunteers is associated with increased intrasphincteric acid reflux and lengthening of the cardiac mucosa. Gastroenterology. 2013;145:730-9.

67. Quante M, Abrams JA, Wang TC. The rapid rise in gastroesophageal junction tumors: is inflammation of the gastric cardia the underwater iceberg? Gastroenterology. 2013;145:708-22.
68. McQuaid KR, Laine L, Fennerty MB, Souza R, Spechler SJ. Systematic review: the role of bile acids in the pathogenesis of gastro-oesophageal reflux disease and related neoplasia. Aliment Pharmacol Ther. 2011;34:146-65.

69. Watanabe M, Houten SM, Mataki C, Christoffolete MA, Kim $\mathrm{BW}$, Sato $\mathrm{H}$, et al. Bile acids induce energy expenditure by promoting intracellular thyroid hormone activation. Nature. 2006;439:484-9.

70. Watanabe M, Morimoto K, Houten SM, Kaneko-Iwasaki N, Sugizaki $\mathrm{T}$, Horai $\mathrm{Y}$, et al. Bile acid binding resin improves metabolic control through the induction of energy expenditure. PLoS ONE. 2012;7:e38286.

71. Dixon MF, Mapstone NP, Nelville PM, Moayyedi P, Axon AT. Bile reflux gastritits and intestinal metaplasia at the cardia. Gut. 2002;51:351-5.

72. Bowrey DJ, Williams GT, Carey PD, Clark GW. Inflammation at the cardio-oesophageal junction: relationship to acid and bile exposure. Eur J Gastroenterol Hepatol. 2003;15:49-54. 